\title{
Particulate matter from tobacco versus diesel car exhaust: an educational perspective
}

\author{
G Invernizzi, A Ruprecht, R Mazza, E Rossetti, A Sasco, S Nardini, R Boffi
}

Tobacco Control 2004;13:219-221. doi: 10.1136/tc.2003.005975

\begin{abstract}
Background: Air pollution is a common alibi used by adolescents taking up smoking and by smokers uncertain about quitting. However, environmental tobacco smoke (ETS) causes fine particulate matter (PM) indoor pollution exceeding outdoor limits, while new engines and fuels have reduced particulate emissions by cars. Data comparing PM emission from ETS and a recently released diesel car are presented. Methods: A $60 \mathrm{~m}^{3}$ garage was chosen to assess PM emission from three smouldering cigarettes (lit sequentially for 30 minutes) and from a TDCi $2000 \mathrm{cc}$, idling for 30 minutes.

Results: Particulate was measured with a portable analyser with readings every two minutes. Background $\mathrm{PM}_{10}, \mathrm{PM}_{2.5}$, and $P M_{1}$ levels (mean (SD)) were $15(1), 13(0.7)$, and 7 (0.6) $\mu \mathrm{g} / \mathrm{m}^{3}$ in the car experiment and $36(2), 28(1)$, and $14(0.8) \mu \mathrm{g} / \mathrm{m}^{3}$ in the ETS experiment, respectively. Mean (SD) PM recorded in the first hour after starting the engine were $44(9), 31(5)$, and $13(1) \mu \mathrm{g} / \mathrm{m}^{3}$, while mean PM in the first hour after lighting cigarettes were 343 (192), 319 (178), and $168(92) \mu \mathrm{g} / \mathrm{m}^{3}$ for $\mathrm{PM}_{10}, \mathrm{PM}_{2.5}$, and $P M_{1}$, respectively ( $p<0.001$, background corrected).

Conclusions: ETS is a major source of PM pollution, contributing to indoor PM concentrations up to 10-fold those emitted from an idling ecodiesel engine. Besides its educational usefulness, this knowledge should also be considered from an ecological perspective.
\end{abstract}

A ir pollution caused by particulate matter $(\mathrm{PM})$ is a risk factor for chronic obstructive pulmonary disease and asthma, and for lung cancer. ${ }^{1-3}$ In addition, it has been shown that each increase of $10 \mu \mathrm{g} / \mathrm{m}^{3}$ in ambient PM levels carries a short term health burden that can be calculated in terms of morbidity and mortality, ${ }^{4}$ and is perceived as a serious threat by lay persons and decision makers. Accordingly, official annual average PM limits have been set at $40 \mu \mathrm{g} / \mathrm{m}^{3}$ for $\mathrm{PM}_{10}$ in Europe, and at $15 \mu \mathrm{g} / \mathrm{m}^{3}$ for $\mathrm{PM}_{2.5}$ in the USA.

Environmental tobacco smoke (ETS) presents health risks similar to those of air pollution in regard to respiratory and cardiovascular diseases, ${ }^{1-35}$ and is being counteracted by regulations in most countries. ${ }^{6}$ Nonetheless even health personnel are often unaware of such risks, and paradoxically, the presence of air pollution is commonly utilised as an alibi by smokers in an attempt to minimise the health risk linked to tobacco smoking. ${ }^{7}$

The composition of ETS is similar to other fossil fuel combustion products that contribute to air pollution, and has been shown to be responsible for indoor PM levels far exceeding official outdoor limits. ${ }^{8}{ }^{9}$ This knowledge can be used to develop an educational message on smoking prevention based on indoor versus outdoor pollution, an issue of concern also for the tobacco industry, as disclosed by the attempts to produce cigarettes with low PM emissions. ${ }^{10}$

An additional message could derive from the comparison between PM production by cigarettes and by the new low emission cars. It has been estimated that older gasoline vehicles and light duty diesel emission rates are on average 100 times higher than those of newer vehicles, and that cars and trucks manufactured from 1991-1996 currently account for only $3.8 \%$ of PM pollution, as compared to $26.8 \%$ caused by cars built from 1986-1990. ${ }^{11}$ In addition, low sulfur fuel for diesel engines reduces secondary PM formation. ${ }^{12}$ To explore the issue, we carried out an experimental study to compare PM production from ecodiesel exhaust and smouldering cigarettes.

\section{METHODS}

The experiments were carried out in Chiavenna, a small mountain town in northern Italy, chosen because of usually low outdoor PM levels. A private garage of $60 \mathrm{~m}^{3}$ with a balancing door endowed with six small vents of $25 \mathrm{~cm}^{2}$ each (kept always opened as required by law to ensure continuous air exchange), was the setting for a series of measurements. Recordings of 40 minutes were done with the door open before each experiment to measure background PM levels, then the door was kept closed until the end of the experiment. Between each experiment the door was kept open for at least four hours to obtain adequate air exchange.

In the first phase of the experiment a diesel engine was started and left idling (760 rpm) for 30 minutes. In the second phase, three cigarettes were sequentially lit up and left smouldering for an overall period of 30 minutes. Recordings were continued for an additional 90 minutes. The car was a turbo diesel common rail 2.0 litre Ford Mondeo, year 2002, that complied with the Euro3 gas exhaust standards. The engine was fuelled with low sulfur "bludiesel" fuel produced by AGIP (a consociate of ENI, the Italian Hydrocarbons Agency), containing only 10 parts per million of sulfur $(10 \mathrm{mg} / \mathrm{kg})$ which helps to minimise PM production. ${ }^{13}$ Filter cigarettes of a national brand ("MS" filter cigarettes produced by Italian State Monopoly) were used, with a nicotine content of $1 \mathrm{mg}$ and a tar content of $11.2 \mathrm{mg}$. The cigarettes were left smouldering at the same location as the exhaust mouthpiece, $3 \mathrm{~m}$ from the analyser that was placed at a height of $1.5 \mathrm{~m}$.

PM was measured with a portable, laser operated aerosol mass analyser (Aerocet 531, Metone Instruments Inc, USA) with readings every two minutes. The instrument calculates $\mathrm{PM}_{10}, \mathrm{PM}_{2.5}$, and $\mathrm{PM}_{1}$ concentrations, expressed in $\mu \mathrm{g} / \mathrm{m}^{3}$. The sensor is factory calibrated using PLS (polystyrene latex) calibration particles but, since differences in the morphology, composition, temperature, humidity, and optical characteristics of the aerosol to be measured can introduce errors,

Abbreviations: ETS, environmental tobacco smoke; PM, particulate matter 
a re-calibration for ETS was performed by comparison with gravimetric determination according to the norms in use presently in Italy (appendix 2 of D.P.C.M. 28/03/1983). ${ }^{14}$

Even though official limits have not yet set for $\mathrm{PM}_{1}$, its concentrations are reported in detail because it's closer to the class of ultrafine particles which are especially dangerous to the lung, and because it is present at high levels in both ETS and exhaust gas. ${ }^{10} 11$ Paired comparisons (diesel versus cigarettes) of repeated measurements taken every two minutes were evaluated by two sided Student's $t$ test.

\section{RESULTS}

The data shown in fig 1 represent one set of results from three different replicates that gave overlapping data. Official (ARPA, the Italian Environmental Protection Agency) $\mathrm{PM}_{10}$ 24 hour average for the day in which the reported experiments were carried out was $55 \mu \mathrm{g} / \mathrm{m}^{3}$. In the diesel experiment the mean (SD) background levels recorded were 15 (1), 13 (0.7), and 7 (0.6) $\mu \mathrm{g} / \mathrm{m}^{3}$ for $\mathrm{PM}_{10}, \mathrm{PM}_{2.5}$, and $\mathrm{PM}_{1}$, respectively, while in the ETS experiment, recorded four hours later, the background was $36(2), 28(1)$, and 14 (0.8) $\mu \mathrm{g} / \mathrm{m}^{3}$ for $\mathrm{PM}_{10}, \mathrm{PM}_{2.5}$, and $\mathrm{PM}_{1}$, respectively. The mean (SD) PM levels recorded in the first hour after starting the engine were 44 (9), 31 (5), and 13 (1) $\mu \mathrm{g} / \mathrm{m}^{3}$, while the PM levels in the first hour after lighting the cigarettes were 343 (192), 319 (178), and $168(92) \mu \mathrm{g} / \mathrm{m}^{3}$ for $\mathrm{PM}_{10}, \mathrm{PM}_{2.5}$, and $\mathrm{PM}_{1}$, respectively $(\mathrm{p}<0.001$, Student's $t$ test, corrected for background, for comparisons between each PM class). The diesel engine increased PM levels to a maximum of doubling outdoor values, while ETS contributed to a peak of 15-fold outdoor PM concentrations. It's remarkable that PM decay after cigarette smoking was very slow, with $\mathrm{PM}_{10}$ concentrations over $300 \mu \mathrm{g} / \mathrm{m}^{3}$ lasting for up to one hour (time 42 to 102 minutes in fig 1), while $\mathrm{PM}_{10}$ and $\mathrm{PM}_{2.5}$ levels exceeded outdoor limits up to about an hour and a half, at the end of the experiment.

\section{DISCUSSION}

ETS was shown to be a much higher source of pollution than an ecodiesel engine in regard to PM emission. In fact three cigarettes smouldering in a room of $60 \mathrm{~m}^{3}$ with a limited air exchange, a setting commonly encountered in everyday life, were able to produce PM concentrations up to 10-fold that of the engine's emissions, and up to 15 -fold $\mathrm{PM}_{10}$ and $\mathrm{PM}_{2.5}$ outdoor limits, in agreement with previous data on ETS pollution observed in the hospitality industry. ${ }^{8} 9$

The differences in background levels between the two experiments can be explained by daily fluctuations in outdoor PM, and have been taken into account for statistical evaluation.

As for the reliability of the analysis, the analyser has been calibrated using a certified reference instrument. ${ }^{14}$ Data reproducibility can also be accounted for by the repeatability of background recordings for any single PM class in both the experiments (time 0-40 minutes in fig 1), and by their satisfying agreement with the official $\mathrm{PM}_{10}$ averages, taking into account the different location of the ARPA's station (located in a place with more intense road traffic), and the fact that the official value is the 24 hour average, while the measured ones represented 40 minutes average.

In a recent report by Salvi and colleagues, ${ }^{15}$ healthy nonsmoking volunteers were exposed for one hour to $\mathrm{PM}_{10}$ concentrations of $300 \mu \mathrm{g} / \mathrm{m}^{3}$ generated from an idling (680 rpm) diesel engine (turbodiesel, year 1991): shortly after the exposure, a pronounced systemic and pulmonary inflammatory response was observed. This report is relevant to our data since the setting was similar, except for the employment of an older type of diesel engine with high emission rates in the study by Salvi and colleagues, where exhaust had to be diluted with $90 \%$ air to reach the PM concentrations of $300 \mu \mathrm{g} / \mathrm{m}^{3}$ established for their experiment. In our experiment too, $\mathrm{PM}_{10}$ produced by cigarettes reached concentrations of over $300 \mu \mathrm{g} / \mathrm{m}^{3}$ which persisted for one hour.

Although individual specificities characterise single sources of different products, combustion aerosols share many chemical components and show similar aerodynamic profiles. ${ }^{16}$ Accordingly, it has been shown that ETS and diesel exhausts share many common chemical components such as hydrocarbons, aldehydes, nitric oxides, carbon dioxide, and carbon monoxide, and have similar PM emissions, composed primarily of particles $<2.5 \mu \mathrm{m}$ in diameter. ${ }^{10}{ }^{11}$

Since we utilised a room with a volume similar to that encountered in many offices and homes, the present data give cause for concern; this is because high level PM exposure generated by ETS could account for frequent subclinical episodes of short term respiratory damage in non-smokers due to the long time spent indoors and the fact that ventilation systems cannot efficiently control ETS

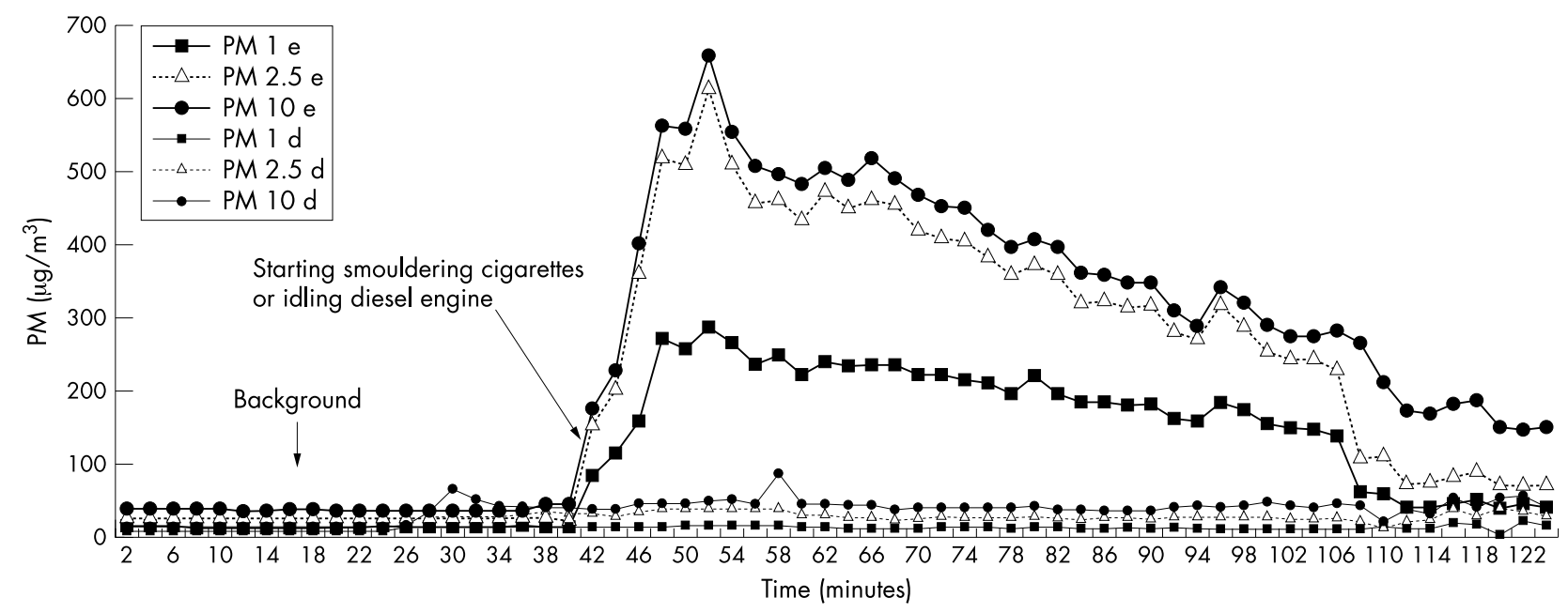

Figure 1 Particulate matter (PM) production from environmental tobacco smoke (e) and an ecodiesel engine (d) (three smouldering cigarettes or an idling engine for 30 minutes in a $60 \mathrm{~m}^{3}$ garage). 


\section{What this paper adds}

Environmental issues are leading manufacturers to lend more attention to vehicle exhaust, and emissions from new cars pollute much less than before. The present data show that cigarettes produce higher particulate matter pollution than diesel exhaust. This message fits particularly with adolescents' concerns about the environment and can be used as a convincing anti-tobacco issue.

pollution. ${ }^{6}{ }^{17}$ The negative comparison of ETS in respect to traffic pollution can be a valuable educational message. Furthermore, from an ecological perspective-especially when addressed to adolescents-ETS could be considered to be one of the main residual contributors to air pollution. ${ }^{1}$

\section{ACKNOWLEDGEMENTS}

We are indebted to Franco Berrino and Giorgio Parmiani (National Cancer Institute, Milan) for helpful discussion.

\section{Authors' affiliations}

G Invernizzi, A Ruprecht, R Mazza, E Rossetti, R Boffi, Tobacco Control Unit, National Cancer Institute SIMG-Italian Academy of GPs, Milan, Italy

A Sasco, IARC, Lyon, France

S Nardini, Pulmonary \& TB Unit, General Hospital, Vittorio Veneto, Italy

Correspondence to: $\mathrm{G}$ Invernizzi, National Cancer Institute, Tobacco Control Unit, 17 via Della Michela, Prata Camportaccio, 23020, Italy; ginverni@clavis.it

Received 5 September 2003

Accepted 23 January 2004

\section{REFERENCES}

1 Kunzli N. The public health relevance of air pollution abatement. Eur Respir J 2002; 20:198-209.

2 Viegi G, Annesi I, Matteelli G. Epidemiology of asthma. Eur Respir Mon 2003;8:1-25.

3 Pope III CA, Burnett RT, Thun MJ, et al. Lung cancer, cardiopulmonary mortality, and long-term exposure to fine particulate air pollution. JAMA 2002; 287:1132-41.

4 Samet JM, Dominici F, Curriero FC, et al. Fine particulate air pollution and mortality in 20 U.S.cities, 1987-1994. N Engl J Med 2000;343:1742-9.

5 IARC. The IARC Monograph 83 on involuntary smoking. IARC Monographs 2004.

6 Board of Science and Education \& Tobacco Control Resource Centre. Towards smoke-free public places. London: BMJ Books 2002.

7 Nardini S, Bertoletti R, Rastelli V, et al. The influence of personal tobacco smoking on the clinical practice of Italian chest physicians. Eur Respir J $1998 ; 12: 1450-3$

8 Repace JL, Lowrey AH. Indoor air pollution, tobacco smoke, and public health. Science 1980;208:464-72.

9 Invernizzi G, Ruprecht A, Mazza R, et al. Real-time measurement of indoor particulate matter originating from environmental tobacco smoke: a pilot study. Epidemiol Prev 2002;26:30-4.

10 Nelson PR, Kelly SP, Conrad FW. Studies of environmental tobacco smoke generated by different cigarettes. J Air Waste Manage Assoc 1998:48:336-44.

11 Cadle SH, Mulawa P, Hunsanger EC, et al. Light-duty motor vehicle exhaust particulate matter measurement in the Denver, Colorado, area. J Air Waste Manage Assoc 1999;49:164-74.

12 Lloyd AC, Cackette TA. Diesel engines: environmental impact and control. J Air Waste Manag Assoc 2001:51:809-47.

13 ENI. ENI Annual Report 2002. http://212.180.4.141/swim/files/us/ IT0003132476_01_Eni_Annual_Report_2002_2.6_Mo.pdf [Accessed 17 Dec 2003]

14 Boffi R, Ruprecht A, Invernizzi G, et al. Monitoring indoor environmental tobacco smoke particulate matter with a low cost, user-friendly portable analyzer: reproducibility and reliability. Am J Crit Care Med 2003;167:A500.

15 Salvi S, Blomberg A, Rudell B, et al. Acute inflammatory responses in the airways and peripheral blood after short-term exposure to diesel exhaust in healthy human volunteers. Am J Respir Crit Care Med 1999;159:702-9.

16 Lighty JAS, Veranth JM, Sarofim AS. Combustion aerosols: factors governing their size and composition and implications to human health. J Air Waste Manage Assoc 2000;50:1565-618.

17 Repace J, Kawachi I, Glantz S. Fact sheet on secondhand smoke. UICC 1999

\section{The Lighter Side}
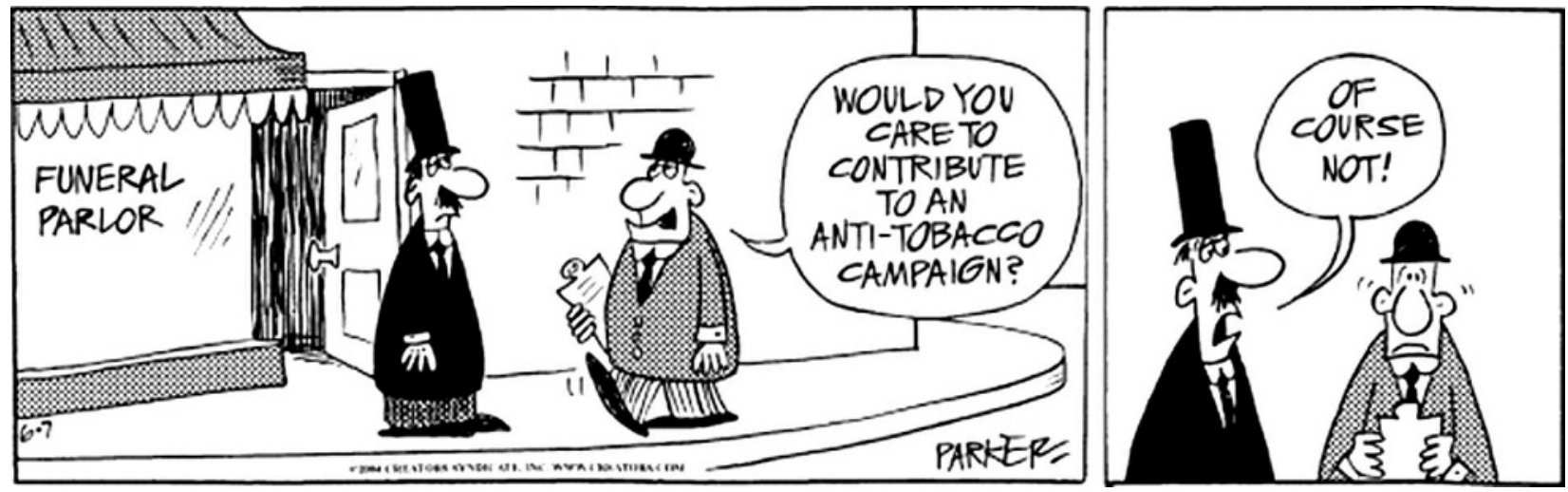

Parker \& Hart, Wizard of ld

(C) 2004 Creators Syndicate, Inc 